\begin{tabular}{|c|c|c|c|c|c|c|}
\hline \multirow{4}{*}{ Impact Factor: } & ISRA (India) & $=3.117$ & SIS (USA) & $=0.912$ & ICV (Poland) & $=6.630$ \\
\hline & ISI (Dubai, UAE & $=0.829$ & РИНЦ (Russia) & $=0.156$ & PIF (India) & $=1.940$ \\
\hline & GIF (Australia) & $=0.564$ & ESJI (KZ) & $=8.716$ & IBI (India) & $=4.260$ \\
\hline & JIF & $=1.500$ & SJIF (Morocco) & $=5.667$ & OAJI (USA) & $=0.350$ \\
\hline
\end{tabular}

SOI: $1.1 /$ TAS $\quad$ DOI: $10.15863 / T A S$
International Scientific Journal
Theoretical \& Applied Science
p-ISSN: 2308-4944 (print) $\quad$ e-ISSN: $2409-0085$ (online)
Year: $2019 \quad$ Issue: $03 \quad$ volume: 71
Published: $19.03 .2019 \quad \underline{\text { http://T-Science.org }}$

UDC: 809.43

SECTION 21. Pedagogy. Psychology. Innovations in the field of education.
QR - Issue

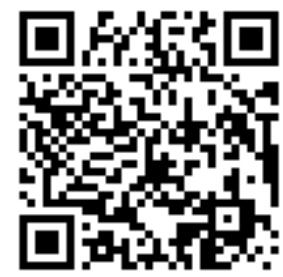

\title{
ADVERTISING IN THE DICTIONARY OF M.KASHGARI "DIVANU LUGATI AT-TYURK" AND THEIR COMMUNICATION WITH CONTEMPORARY THE KYRGYZ LANGUAGE
}

\begin{abstract}
The article deals with the education and classification of adverbs in the Mahmud Kashgari dictionary "Divan lugati at-Turk", and their relationship with the adverbs of the modern Kyrgyz language. In the dictionary you can find a fairly large number of adverbs. Adverbs according to the method of education are divided into derivatives and non-derivatives. It is known that in modern Kyrgyz language, adverbs are derived from case affixes. The fact that such a method of forming adverbs is one of the ancients turned out from the dictionary of M. Kashgari: a) an affix, standing in the form of the dative-directional case or indicating the direction; $b$ ) adverbs, formed with the help of the affix of the local case; c) adverbs formed with the help of the affix of the dative-directional case. Adverbs from the Mahmud Kashgari dictionary can be divided into the following digits by value: adverbs of time, adverbs of place, adverbs of mode of action, adverbs of measure and degree.

Key words: ancient phenomena, vocabulary, vocabulary of the language, written monument, modern Kyrgyz language, derived and non-derivative adverbs, phonetic changes, noun meaning, dialect, antonymic meaning, nouns, numerals, verbs, adverbs, morphological ways, syntactic way, word-forming affixes, suffix, root of the words, phonetic change, case compound word affixes, service words, compound words, merged words, adverbs of time, adverbs of place, adverbs of image actions, adverbs of measure and degree.

Language: Russian

Citation: Davlatova, S. J. (2019). Advertising in the dictionary of M.Kashgari "Divanu lugati at-tyurk" and their communication with contemporary the Kyrgyz language. ISJ Theoretical \& Applied Science, 03 (71), 342-347.

Soi: http://s-o-i.org/1.1/TAS-03-71-21 Doi: crossef https://dx.doi.org/10.15863/TAS.2019.03.71.21

\section{НАРЕЧИЯ В СЛОВАРЕ МАХМУДА КАШГАРИ “ДИВАНУ ЛУГАТИ АТ-ТЮРК” И ИХ СВЯЗЬ С СОВРЕМЕННЫМ КЫРГЫЗСКИМ ЯЗЫКОМ}

Аннотация: В статье рассматриваются вопросы образовании и классификации наречий в словаре Махмуда Кашгари “Дивану лугати ат-тюрк”, и их соотношение с наречиями современного кыргызского языка. В словаре можно найти довольно больиое количество наречий. Наречия по способу образования делятся на производные и непроизводные. Производные наречия можно делить на две группы: образованные морфологичксим способом и образованные синтаксическим способом. Известно, что в современном кыргызском языке производные наречия образуются с помощью падежных аффиксов. То, что такой способ образования наречий является одним из древних, выяснилось из словаря М.Кашгари: аффикс, стоящий в форме дательно-направительного падежа или указывающий на направление; наречия, образованные с помощьюю аффикса местного падежа; наречия, образованные с помощью аффикса дательнонаправительного падежа. Таким образом, больиинство наречий из словаря великого лингвистаэнцииклопедиста Махмуда Кашгари “Дивану лугати ат-түрк” (“Собрание тюркских нарчеий”) встречаются в современном в кыргызском языке как в сохраненном, так и в изменённом видах. Отдельные наречия в настоящее время вышли из употребления.
\end{abstract}




\begin{tabular}{|c|c|c|c|c|c|c|}
\hline \multirow{4}{*}{ Impact Factor: } & ISRA (India) & $=3.117$ & SIS (USA) & $=0.912$ & ICV (Poland) & $=6.630$ \\
\hline & ISI (Dubai, UAE & $=0.829$ & РИНЦ (Russia & $=0.156$ & PIF (India) & $=1.940$ \\
\hline & GIF (Australia) & $=0.564$ & ESJI (KZ) & $=8.716$ & IBI (India) & $=4.260$ \\
\hline & JIF & $=1.500$ & SJIF (Morocco & $=5.667$ & OAJI (USA) & $=0.350$ \\
\hline
\end{tabular}

Ключевые слова: древние явления, лексический запас, лексика языка, письменный памятник, современный кыргызский язык, производные и непроизводные наречия, фонетические изменения, значение существительных диалект, антонимическое значение, имя существительные, имя числительные, глаголь, наречия, морфологичксий способ, синтаксический способ, словообразующие аффиксы, суффикс, корень слов, фонетическое изменение, падежные аффиксы сложного слова, служебные слова, сложные слова, слитные слова, наречия времени, наречия места, наречия образа действия, наречия меры и степени.

\section{Introduction}

Написанный еще в средневековье и дошедший до нас словарь «Дивану лугати аттюрк» лингвиста-энциклопедиста Махмуда Кашгари является бесценным лингвистическим достоянием и историческим наследием всех тюрских народов. Этот словарь имеет огромное значение для исследования лексики тюрских языков в историческом аспекте. В словаре встречается большинство слов лексического фонда современного кыргызского языка.

Данная статья посвящена вопросам способов образования и классификации наречий по значению, а также выявлению их соотношения с наречиями современного кыргызского языка.

Наречиями называется слова, относящиеся к глаголу, обозначающие признак действия и выполняющие в предложении роль обстоятельства.

\section{Materials and Methods}

В словаре можно найти довольно большое количество наречий. Наречия по способу образования делятся на производные и непроизводные. К непроизводным наречиям можно отнести следующие: ӧ - мурун, алдыда (раньше): ol mändän öๆdün bard - ал менден мурун (менин алдымда) барды (Он пошел раньше меня). ilk - алды менен, абалы (сначала): ilk sän barğıl алды менен сен баргын (Сначала иди ты), qužı төмөн [1,126]:

Jvrıq bași qazlaju,

Sağraq tolu közläjü,

Saqınç qužı kizläjü,

Tün-kün bilä sävnätim.

Кумган башы каздайым,

Сагадан толо көздөйүм,

Кайгыны төмөн көмөйүн,

Сүйүнөйүн күнү-түн.

(Милая моя, с головой как у кувшина, с глазами чарующими, я хороню свою печаль, буду радоваться днём и ночью). äz - аз: äz mä - аз нерсе (мало). șap - шап, тез (быстро: șap käl -тез кел (приди быстро). bat - бат, ылдам (скореe): bat käl - бат кел (приди скореe). dik - тик (прямо вверх): dik turdi - тик турду (встал прямо вверх). tärk - тез, бат (быстро): tärk käl. тиң - тик (прямо вверх): ер тиң турды - эр тик турду (мужчина встал прямо вверх). кич - кеч (поздно): кич келди - кеч келди (пришел поздно). соң- соң, кийин (после, за кем/чем-то): сен мениғ соңда кел - сен менин соңумдан кел (ты иди за мной); бу сөз соңында айғыл - бул сөздү сонунда айткын (это слово скажи в конце) [1,336].

емди - эми:

таң ата йорталым

бузруч қанын иртелим

йасмыл бегин өртелим

емди йигит йавулсун

Таң ата жортуулдайын

Бузруч канын талап кылабыз, өч алалы деп

Йасмыл бегин өрттөйлү,

Эми (биздин) жигиттер жабылсын.

Производные наречия можно делить на две группы: образованные морфологичксим способом и образованные синтаксическим способом.

В словаре Махмуда Кашгари обнаруживаются наречия, образованные морфологичским способом с помощью следующих аффиксов:

-uq(-q): artuq - артык (ашыкча, артыкча) (лишнее, больше) [1,125 ]: ortaq ärdän artuq almas дос эрден артык албас; (друг не берёт больше, чем богатырь) artuq- артык [2, 109]: juğurqanda artuq ažaq kösülsä üșijür - жууркандан артык сунулса, аяк үшүр (если отпускать ноги больше, чем одеяло - ногам будет холодно). Корень art в древнетюрском словаре имел значение увеличивается, прибавляться. Это слово сохранилось в современном кыргызском языке в том же значении.

uzaq - узак (далеко) [1, 93]: jalawaç uzaq bardı - элчи узак барды элчи узак барды (посол пошел далеко). В древнетюркском словаре слово $o z$ имеет значение опережать. И в современном кыргызском языке оно употребляется в неизмененном виде и по звуковому составу, и по значению.

тевреқ-тезирээк (скорее, быстрее):

үндеп улуғ тапару

тевреқ келип йүгүрғил

курғақ йылын бузун көр

қанда түшер куды йыл

Үндөп улуу чакырса,

Тезирээк келип жүгүр,

Кургак(чылык) жылдарда элди көр,

Кайда көчүшөр, алар бирге жыл (көч).

Слово tapri в древнетюрском словаре обозначает “скакать", “подпрыгивать”. Предполагается, что слово тевреқ образовано от слова tapri, т.к.в слове тевреқ также имеется значение движения.

- $a$ : jämä - кайта, кайра [3, 133] :

Toqli böri qajtılsun, 


\begin{tabular}{|c|c|c|c|c|c|c|}
\hline \multirow{4}{*}{ Impact Factor: } & ISRA (India) & $=\mathbf{3 . 1 1 7}$ & SIS (USA) & $=0.912$ & ICV (Poland) & $=6.630$ \\
\hline & ISI (Dubai, UAE & $=0.829$ & РИНЦ (Russia & $=0.156$ & PIF (India) & $=1.940$ \\
\hline & GIF (Australia) & $=0.564$ & ESJI (KZ) & $=8.716$ & IBI (India) & $=4.260$ \\
\hline & JIF & $=1.500$ & SJIF (Morocco & $=5.667$ & OAJI (USA) & $=0.350$ \\
\hline
\end{tabular}

Qažğu jämä savilsun.

Токту, бөрү жарышсын,

Кайгы кайта адашсын.

Слово јӓm в древнетюркском словаре имеет значение "возвращаться" и видно, что с помощью суффикса - $a$ образованом наречие от глагола. Данный суффикс отмечен и в древнетюркском словаре как суффикс, образующий наречие. Слово жана хотя сохранилось в современном кыргызском языке, оно имеет временно́е значение. А в узбекском языке сохранилось в форме јӓпӓ и употребляется в том же значении.

йана - жана, экинчи жолу (снова, второй раз): йана келди - жана келди (снова пришел/прибыл). И в данном примере наречие дает значение “второй раз, снова".

кече- кеч, кечкурун (вечером, вечерком): кече туруп йүрир ердим - кечеси туруп, жүрө бердим (ночью вставал и ходил).

-n: зафиксирован в древнетюркском словаре как аффикс, образующий наречие от существительных и приведено в качестве примера слово jazın. Из словаря можно привести следующие примеры на слова, образрованные с помощью данного суффикса:

йазын - жазында (весной), қышын кышында (зимой) [3, 241]: йазын қатығланса қышын севнур - жазында кыйналса, кышында сүйүнөр (трудно весной - радостно зимой). Эти наречия употребляется в таком же виде и в современном кыргызском языке, более всего широко используются формы жазында, кышында (весной, зимой).

timin (tämin) - жакын, мурун: tämin käldim жакын келдим.

ärkän - кайра (опять): ol mạa larmaq birür ärkän qatrundı - ал мага теңге берип жатып, кайра айнып кетти (он мне давал монеты, но опять передумал). В древнетюркском словаре ärk̈̈ обозначает “спина" и в своременном кыргызском языке употребляется без фонетических изменений. Однако слово ärkän не употребляется, а широко употребляется слово артка (кайтты) / назад (вернулся).

- $n$ с помощью данного суффикса образуются наречия и от других частей речи:

узун (длинный) - узак (долго): ер узун йашады - эр узак жашады (мужчина жил долго).

üstün - ycmY, жогору (верх, выше) : andan üstün - андан жогору, анын үстүндө (выше него, над ним)

- astın - acmbl [5, 135.] (под ...);

kižin - кийин (позади): $\ddot{a} r$ kižin qaldı - эp

кийин калды (мужчина остался позади);

ақрун- акырын (осторожно):

болмыш неңиң север сен

ақрун аңар севингил

бармуш неңиг сақынма

азрақ аңар өкүңил
Болгон байлыгыңа сүйүнөрсүң,

Акырын ага сүйүнгүн,

Бурбаган байлыгыңа кайгырба,

Азыраак ага өкүнгүн.

(Радуешься тому богатству, что у тебя есть, радуйся осторожно, Не печалься за богатство, которое тебе не досталось, меньше расстраивайся за него).

-tin:öndün - мурун, алдыга [1,142] (вперёд, раньше): öๆdün jürüt - алдыга (алдын) бастыр (иди вперёд /раньше). Это слово сохранилось в южном диалекте современного кыргызского языка: Мен алдын келдим (Я пришел раньще). В словаре это дано как аффикс, образующий наречие, и отмечено, что ӧๆ- обознчнает “восток”. В словаре М.Кашгари ӧ обозначает раньше, вперёд можно предполагать, что слово ӧпdün образовано от этого корня.

-lä: - birlä- бирге (вместе, совместно) [2, 68]: ol mäni тебишти (он играл вместей со мной). Здесь видно, что с помощью данного суффикса образовано наречие от числительного.

бирле - бирге (вместе): ол аныг бирле ат йарышды - ал аны менен бирге ат чабышты (он скакал на коне вместе с ним).

Слово birlä в таком же виде встречается в современном узбекском языке (Мени билан бирла окуйди - Учится вместе со мной), а в своременном кыргызском языке претерпев фонетическое изменение, -lä перешло в -гa.

түнла - түндө (ночью), күндүз - күндүз (днём): түнла йүрүп күндүз севнүр кичикда евленип йлвазу севнур - түндө жүрүп күндүзү сүйүнөр (анткени басып өткөн көрбөйт) (идущий ночью радуется днём/дню).

йаңыла - заново, снова: ол ишиғ йаңыла қылды - ал ишин жаңылай (экинчи жолу, кайра) кылды (он выполнил работу заново). Это слово встречается в современном кыргызском языке в формах (вариантах) жаңзылай, жаңъыча.

-u (-i): užu - арты, артынан: män anıๆ užu käldim - мен анын артынан келдим.

кече- кеч, кечкурун (вечером, вечерком): кече туруп йүрир ердим - кечеси туруп, жүрө бердим (ночью вставал и ходил). Это слово употребляется и в современном кыргызском языке.

Известно, что в современном кыргызском языке производные наречия образуются с помощью падежных аффиксов. То, что такой способ образования наречий является одним из древних, выяснилось из словаря М.Кашгари:

a) аффикс, стоящий в форме дательнонаправительного падежа или указывающий на направление:

- $\operatorname{aru}(-r u,-u)$ : joqaru - жогору, өйдө (вверх): ol joqaru jarın sağurdı - ал жогору карап түкүрдү (он плюнул вверх); är joqaru turdı - эр өйдө турду (мужчина поднялся (вверх)). Јиқ - юқори (жогору) 


\begin{tabular}{|c|c|c|c|c|c|c|}
\hline \multirow{4}{*}{ Impact Factor: } & ISRA (India) & $=\mathbf{3 . 1 1 7}$ & SIS (USA) & $=0.912$ & ICV (Poland) & $=6.630$ \\
\hline & ISI (Dubai, UAE & $=0.829$ & РИНЦ (Russia & $=0.156$ & PIF (India) & $=1.940$ \\
\hline & GIF (Australia) & $=0.564$ & ESJI (KZ) & $=8.716$ & IBI (India) & $=4.260$ \\
\hline & JIF & $=1.500$ & SJIF (Morocco & $=5.667$ & OAJI (USA) & $=0.350$ \\
\hline
\end{tabular}

(высоко, вверх) образовано от слова баландлик(бийиктик) (высота).

утру - утуру, алдынан (снова, спереди): йылан йарбуздын қачар қанча барса йарбуз утру келур - жылан мангустан качар, канча качса да мангус утуру (алдынан) чыгар (змея бежит от мангусты, а мангуста снова появится спереди).

йурру - жакын (рядом): ол аңар йуғру йүрмас - Ал ага жакын жүрбөс (он рядом не ходит). На самом деле "йакру” близко к букве $к$, вместо которой стоит буква в.

juqar - өйдө (высоко, вверх):

Qut quvığ bärsä ižim qulına

Kündä iși jüksädän juqar ağar.

Кут, дөөлөттү берсе эгем кулуна,

Ишим оңолот, ташы өйдө куланар.

(Если даст всевышний даст богатство своему рабу,

То дела его исправятся, камень упадёт вверх): в данном примере камень упадет вверх фразеологизм, означающий “дела уладятся).

кирү- артка (назад):

бардың нелек аймадың

кирү көрүп қаймадың

көңүл берү йаймадың

болдун еринч болмагу

Бардың (кеттиң) неге айтпадың?

Артка бурулуп карабадың (сыйлап)?

Болдуң эми болбогон (абалга келдиң).

(Почему же пошел, не сказав, Не повернулся назад (из-за уважения)?

Теперь уж случыилось то, что есть).

$o \breve{g} r I$ - төмөн, кийин (низко, после): bu näๆ anıq oğrı ol - это на самом деле низко. Происхождение данного наречия можно связать со словом ig - uй (ийил).

asra - асты, төмөн (внизу, низко).

б) наречия, образованные с помощью аффикса местного падежа:

мунда - мында (здесь): бу йер ол мунда киши йыгылган - бу жер(ге) дайыма мында киши жыйналган (здесь всегда собирались люди). В таком же произносительном варианте встречается в южном диалекте кыргызского языка.

анда- анда (там):

болса кимниг алтун күмүш евле итар

анда болуп теңрикеру табғын утар

Болсо, кимде алтын, күмүш,

Ал үйүн тартипке келтиргендей,

Анда (үйдө) болуп, жайбаракат

бейпилидикте

Аллага табынып жатар.

(Наверное, лежит он у себя там (дома), благославляя Аллаха, будто привел в порядок свой дом).

anda - анда (тогда): man anda ärdim - мен анда(ошол жерде) элем (я тогда (там) был). Из данного примера вытеакет, что это наречие употребляется в современном кыргызском языке без никаких изменений.

қараңкуда - караңгыда (в темноту): ол қараңқуда қарвады - ал караңгыда карбаластады (он суетился в темноту). Видно. что наречие образовано от прилагательного.

соңъында - соңунда, аягында (в конце): бу сөз соңында айғыл - бул сөздү соңунда айткын (это слово скажи в конце).

йаравында - учурунда (в свое время): йиш йарағында сарт асығында - иш учурунда (керек болгон учурда), сарт пайдасында (дело актуально в свое время, сарт на свою пользу). Наречия из последних двух примеров образованы от существительных.

$\ddot{a r t a ̈-~ э р т е ~[1,148] ~(р а н о) . ~ и р ~ п о-ч у в а ш с к и, ~ п о-~}$ туркменски, обозначает рано.

в) наречия, образованные с помощью аффикса дательно-направительного падежа:

бурунқ̧а - мурункуга (предыдущему): соңоқ бурунқа йапрулды - Аягы (соңу) мурункуга жеткирилди, жабышты (конец доведен до предыдущего).

Можно привести примеры из словаря М.Кашгари на наречия, образованные синтаксическим способом и встречающихся в виде собственно сложных слов или слитных слов:

argu - акырын, секин (осторожно): argu-argu - акырын-акырын (осторожно-осторожно/ очень осторожно).

tün-kün-түнү-күнү [1,126] (ночью и днём):

Jvrıq bași qazlaju,

Sağraq tolu közläjü,

Saqınç qužı kizläjü,

Tün-kün bilä sävnätim.

Кумган башы каздайым,

Сагадан толо көздөйүм,

Кайгыны төмөн көмөйүн,

Сүйүнөйүн күнү-түн.

(Милая моя, с головой как у кувшина, с глазами чарующими, я хороню свою печаль, буду радоваться днём и ночью).

Сложное наречие в данном примере представлено в виде собственно сложного слова и имеет антонимическое значение. зарей:

таң ата - таң ата, таңга маал (рано утром, с

таң ата йорталым

бузруч қанын иртелим

йасмыл бегин өртелим

емди йигит йавулсун

Таң ата жортуулдайын

Бузруч канын талап кылабыз, өч алалы деп

Йасмыл бегин өрттөйлү,

Эми (биздин) жигиттер жабылсын.

(Выйду на атаку с зарёй, требуем отомстить против хана Бузруча, сожжём бека Йасмыла, теперь уж джигиты (наши) пусть атакуют). 


\begin{tabular}{|c|c|c|c|c|c|c|}
\hline \multirow{4}{*}{ Impact Factor: } & ISRA (India) & $=3.117$ & SIS (USA) & $=0.912$ & ICV (Poland) & $=6.630$ \\
\hline & ISI (Dubai, UAE & $=0.829$ & РИНЦ (Russia) & $=0.156$ & PIF (India) & $=1.940$ \\
\hline & GIF (Australia) & $=0.564$ & ESJI (KZ) & $=8.716$ & IBI (India) & $=4.260$ \\
\hline & JIF & $=1.500$ & SJIF (Morocco & $=5.667$ & OAJI (USA) & $=0.350$ \\
\hline
\end{tabular}

бір қ̧ата - бир марта (бир жолу) (один раз, раз): бір қата ajlim - бир марта айтдим (бир жолу айттым) (сказал один раз).

В последних двух примерах сложные наречия представлены в виде слитных слов, образованных сочетанием двух слов.

Известно, что в древнетюркском языке аффикс -dır произошел от глагола тур.

bIldir - былтыр, өткөн жыл [1,449] (в прошлом году). Известно, что это слово произошло от словосочетания бир+жылдыр. В древние времена слово бир вступал в атрибутивные отношения со словом жыл. Заметно, что приобретение сложными словами слитной формы есть древнее явление.

А также в словаре встречаются наречия, образованные с помощью служебных слов: ночью):

түн күн табун - түн-күн сайын (днем и

түн күн табун теңриге бойнамағыл

қорқуп аңар айману ойнамаңыл

Түн-күн сайын Теңирге бой көтөрбөгүн,

Коркуп ага ыйман менен ойнобогун.

(Днем и ночью бойся Всевышнего).

В современном кыргызском языке аффикс ыраак образует сравнительную степень наречия. Следующие примеры из словаря доказывают, что наречия, образовавшись с помощью данного аффикса, имели категорию сравнительности еще в древние времена.

-рақ: азрақ - азыраак (меньше): болмыш неңиң север сен

акрун аңар севингил

бармуш неңиг сақынма

азрақ аңар өкүңил

Болгон байлыгыңа сүйүнөрсүң,

Акырын ага сүйүнгүн,

Бурбаган байлыгыңа кайгырба,

Азыраак ага өкүнгүн. (Радуешься тому богатству, что у тебя есть, радуйся осторожно, Не печалься за богатство, которое тебе не досталось, меньше расстраивайся за него).

Наречия из словаря Махмуда Кашгари можно разделить на следующие разряды по значению: наречия времени, наречия места, наречия образа действия, наречия меры и степени.

Наречия образа действия обозначают способ и образ действия и отвечают на вопросы как? каким образом?. Можно привести примеры из словаря: çӓr - бетме-бет, каршы тарап (напротив, сторона напротив): anı ävi bu çärlikädä - его дом находится напротив; șap - шап, тез (быстро): șap käl -тез кел (приди быстро); bat - бат, ылдам (быстро): bat käl; dik - тик (прямо): dik turdı - тик турду (встал прямо); tärk - тез, бат [1,348] (быстро): tärk käl; тиң - тик (прямо): ер тиң турды - эр тик турду (мужчина встал прямо); тунра көмкөрөсүнөн (навзничь): ер тунра түшти - эр жүзү менен көмкөрөсүнөн түштү (мужчина упал лицом навзничь); tägrä- тегерете [2, 12] (кругом):

Tägrä alıp ägrälim

Attın tüșür jügrälim

Arslandaju kökrälim

Küçi anın kävilsin.

Тегерете алып ийрелик,

Аттан түшүп жүгүрөлүк

Арстандай күркүрөйлүк

Күчү анын кемисин.

(Развернувшись кругом, побежим пешком (не верхом), гремим как львы, чтобы его (врага) силы уменьшились).

Наречия меры и степени обозначают меру и степень дейтсвия и отвечают на вопросы сколько? Примеры из словаря: -рақ: азрақ - азыраак (меньше); қамув- түгөл (целиком, полностью): тағдын сувлар қамух куйулушды - тоодон суулар түгөл куюлушту (воды с гор текли целиком); üküş - көп[1,89] (много): tirig äsän bolsa täๆ üküș körür тирүү (жан) эсен болсо, таңды көп көрөт (если душа жива, то увидит зарю много раз); бір қ̧ата бир марта (бир жолу) (раз, один раз): бір қата аjlim - бир марта айтдим - бир жолу айттым (сказал один раз).

Наречия времени обозначают время совершения действия, отвечают на вопросы когда? в какое время?:

түн күн - түнү-күнү (днём и ночью):

үзик мени күчейүр

түн күн туруп йығлайу

көрди көзүм таврақын

йурты қалып ағлайу

Санаа мени кыйнады,

Түн-күн дебей ыйлашты,

Көрдү көзүм (анын) талкаланган үйүн,

Журтту таштап кеткенге шашылганы.

(Переживание мучило меня, плакали днём и ночью,увидели мои глаза его разрушенный дом, как спешили покинуть родное пепелище).

телим- көпкөb (долго): олар телим сайрашты - алар көпкө сайрашты (они (птицы) пели долго); jazın - жазда (весной): küz käligi jazın bälgürär күздүн кандай келери жазда белгилүү болот (какой будет осень известно уже весной); taqI дагы $[2,93]$ (тоже) :

TInı jima öçükti.

Äri atı içikti

Iși taqı çülükti

Sözin anı kim tutar

Деми эми өчүктү (өчтү),

Эрин, атын тапшырды,

Иши дагы бузулду,

Сөзүн анын ким тыңдар..

(Его дух погас, сдал коня и седло, дела тоже испортились, кто же будет слушать его...)

ол - дайыма (всегда): ол кишилер ол йумытган - ал кишилер дайыма жыйналышкан (те люди всегда собирались); соңъында - соңунда, 


\begin{tabular}{|c|c|c|c|c|c|c|}
\hline \multirow{4}{*}{ Impact Factor: } & ISRA (India) & $=3.117$ & SIS (USA) & $=0.912$ & ICV (Poland) & $=6.630$ \\
\hline & ISI (Dubai, UAE & $=0.829$ & РИНЦ (Russia) & $=0.156$ & PIF (India) & $=1.940$ \\
\hline & GIF (Australia) & $=0.564$ & ESJI (KZ) & $=8.716$ & IBI (India) & $=4.260$ \\
\hline & JIF & $=1.500$ & SJIF (Morocco & $=5.667$ & OAJI (USA) & $=0.350$ \\
\hline
\end{tabular}

аягында (в конце/под конец): бу сөз соңында айғыл - бул сөздү сонунда айткын (это слово скажи в конце/под конец); йаравында - учурунда (в свое время): йиш йарағында сарт асығында - иш учурунда (керек болгон учурда), сарт пайдасында (дело актуально в свое время, сарт на свою пользу).; kündüz - күндүз [1, 151] (днем).

amdi- эми (теперь):

Bardı közüm jarudı,

Aldı özüm qunudı,

Qanda ärinç qanıqI,

Amdi özin ožğurur.

Кетти көзүм(дүн) жарыгы,

Алды өзүм(дүн) жанымды,

Кайда экен, канакей,

Эми өзү ойготор.

(Погас свет моих глаз, Забрал душу мою, Где же она, Теперь уж разбудит сама...)

aşnu - мурун, илгери, мурун (раньше): man andan așnu käldim - мен андан мурун келдим (я пришел раньше него).

Наречия места обозначают место совершения действия и отвечают на вопросы где? на каком месте?

мунда- мында (здесь): бу йер ол мунда киши йыгылган - бу жер(ге) дайыма мында киши жыйналган (здесь всегда собирались люди).

anda - анда (там): man anda ärdim - мен анда(ошол жерде) элем (я тогда был (там).

$a c$-ылдыйдан (асты) (внизу):

ус ас көрүп йуксак қалық куды чақар

билге киши үгүт бирип таврақ уқар

Олжону (асты)ылдыйдан көрүп,

Бийиктен бүркүт зымырап учар,

Акылман киши үгүт укса,

Талдап, эске тутар.

(Увидев добычу внизу, беркут слетает свысока, Если мудрый услышит назидание, то запомнит навсегда). киру- артка (назад), еринч - эми (теперь):

бардың нелек аймадың

киру көрүп қаймадың

көңүл берү йаймадың

болдуң еринч болмагу

Бардың (кеттиң) неге айтпадын?

Артка бурулуп карабадың (сыйлап)?

Болдуң эми болбогон (абалга келдиң).

(Почему же пошел, не сказав, Не повернулся назад (из-за уважения)?

Теперь уж случыилось то, что есть).

qat - катарында, жанында [1,324] (рядом):

bäg qatarında - бектин жанында, катарында (рядом с беком, возле бека); бурущ - алыска (далеко): буруң атты - алыска атты (стрелял далеко).

узум - артынан (сзади):

узум барып суңдады

тегре туруп аңдыды

сачын қара маңдады

арзу лайу ер авар

Артынан барып андыды,

Тегеренип кол салайын деди,

Өзү көп адамдын курчоосунда калды,

Кара чачын жулушту (чөө сыяктуу).

(Выслеживал сзади, хотел нападать с круга, а сам остался в окружении многих людей, ему черные волосы выдёргивали (словно шакалу).

\section{Conclusion}

Таким образом, большинство наречий из словаря великого лингвиста-энциклопедиста Махмуда Кашгари “Дивану лугати ат-түрк" (“Собрание тюркских нарчеий”) встречаются в современном в кыргызском языке как в сохраненном, так и в изменённом видах. Отдельные наречия в настоящее время вышли из употребления.

\section{References:}

1. (1969). Drevnetjurkskij slovar' [Tekst] /pod red. V.M.Nadeljaev, D.M. Nasilov, Je.R.Tenishev, A.M.Shherbak (Eds.). (p.676). L.: Nauka.

2. Sartbaev, K. K., Oruzbaeva, B. O., \& Ahmatov, T. K. (1980). Kyrgyz adabij tilinin grammatikasy [Tekst] / zh.b.. 1 belym: Fonetika zh-a morfologija. (p.539). Frunze: Ilim.

3. Koshgorij, M. (1960). «Devonu lugat it-turk» [Tekst] / Mahmud Koshgorij; kotor. S.Mutallibov. (p.468). Toshkent: UzSSR fanlar akademijasi nashrieti, 1960. t-3. - 1963.
4. Kashkari, M. (2013). Divanu lugati-t turk [Tekst]: turkij tilder soz zhyjnagy / Mahmut Kashkari; kotor. I.Avduvaliev, T.Ahmatov, A.Omorov zh.b. (p.511). Bishkek: Bijiktik, t -1.

5. Kashkari, M. (2013). Divanu lugati-t turk [Tekst]: turkij tilder soz zhyjnagy / Mahmut Kashkari; kotor. I.Avduvaliev, T.Ahmatov, A.Omorov zh.b. (p.300). Bishkek: Bijiktik, 2-t.

6. Kashgari, M. (2013). TYrk tilderinin sozdYgY [Tekst] / Mahmud Kashgari; kotor. T. Tokoev, K. Koshmokov. (p.680). Bishkek: AVRASYA PRESS, 3-t. 